\title{
Ödünç Verme Hizmetlerinde iPad: Koç Üniversitesi Suna Kıraç Kütüphanesi Örneği
}

\author{
Circulating iPad: Koç University Suna Kıraç Library
}

Mithat ZENCIR* ve Kamil YEŞILTAŞ**

\begin{abstract}
Öz
Teknolojinin günümüzde geldiği nokta, kütüphaneleri ödünç verme hizmetlerinde kitap ya da kitap türü materyallerin ötesine geçmeye zorlamaktadır. Bu düşünce ile Suna Kıraç Kütüphanesi, uzun süredir ödünç verdiği taşınabilir bellek, diz üstü bilgisayar ve hesap makinesi gibi teknolojik araçlara, 2011 yılında iPad'i de eklemiştir. Yeni sayılabilecek bir teknoloji olan iPad'in kütüphanelerde ödünç verilmesi, gerek politika ve prosedür, gerekse teknik alt yapı yönünden birçok unsuru göz önünde bulundurmayı gerektirmektedir. Bu çalışma, iPad ödünç vermeyi planlayan kütüphaneler için politika oluşturma ve teknik altyapının hazırlanması noktasında gerekli olabilecek bilgileri içermektedir. Ayrıca çalışmada, kullanıcıların iPad kullanımlarına ilişkin yapılmış bir anketin sonuçlarına da yer verilecek, bulgular ışığında iPad ödünç vermeye hazırlanan kütüphanelere önerilerde bulunulacaktır.
\end{abstract}

Anahtar sözcükler: iPad, Ödünç verme hizmetleri, iPad ödünç verme, Teknoloji ödünç verme, Akademik kütüphaneler, Kullanıcı çalışmaları

\begin{abstract}
Today's technology has reached a milestone, that forces library services to go beyond just book lending. With this mind, Suna Kıraç Library has added iPad to its lending list in 2011, which already included technological tools such flash disks, laptops and calculators. While lending this relatively new technological tool, various aspects of loan should be considered and correct policies \& procedures need to be established along with the technical infrastructure. This article provides information on defining policies and creating technical infrastructure that will be useful for libraries that plan to offer iPad lending services. In addition, results of the iPad using survey will be shared in this article. Based on the findings, there will be recommendations provided for libraries that setting up an iPad lending Program in the near future.
\end{abstract}

Keywords: iPad, Borrowing services, Circulating ipad, Technology lending, Academic libraries, User studies

* Referans Kütüphanecisi; Koç Üniversitesi Suna Kıraç Kütüphanesi, İstanbul. (mzencir@ku.edu.tr)

** Referans Kütüphanecisi; Koç Üniversitesi Suna Kıraç Kütüphanesi, İstanbul. (kyesiltas@ku.edu.tr) 


\section{Giriş}

iPad, Apple firması tarafından geliştirilen ve satışa sunulan bir tablet bilgisayardır. 2010 yılı Nisan ayı içerisinde satışa sunulan iPad, satışa çıkmasını takip eden ilk 14 ay içerisinde 25 milyon adet satmış ve kişisel bilgisayar alanında en çok tercih edilen elektronik araçlardan biri olmayı başarmıştır. iPad ile kitap okumak, internette gezinmek, oyun oynamak ve film izlemek gibi aktiviteler aynı anda yapılabilmektedir. Tüm bunların ötesinde bu aktivitelerin esnek, hızlı ve kolay bir şekilde yapılabiliyor olması, kullanıcılar tarafından en çok tercih edilen araç olmasındaki en önemli unsurlar olarak görülmektedir. iPad'lerin yakaladığı popülaritenin bir başka önemli sebebi de, Apple'ın, çevrim içi satış mağazası olan “App Store” üzerinden erişime sunduğu ücretli ya da ücretsiz uygulamalardır. Günümüzde kamu kuruluşları, finansal kuruluşlar, çevrimiçi satış hizmeti sunan ticari kuruluşlar, gazeteler, televizyon kanalları, sosyal medya siteleri, oyun siteleri, üniversiteler ve bilgiye erişim sağlayan yayıncılar gibi birçok organizasyon, kurum ya da kuruluş kendi uygulamalarını hazırlayıp "App Store" üzerinden kullanıma sunmaktadır. Bu uygulamalar ile kullanıcılar, istedikleri anda ilgili kurum ya da kuruluşa kolaylıkla erişebilmektedirler (Griffey, 2012).

Sağladığı kolaylıklarla giderek yaygınlaşan iPad'in, eğitim hizmetleri açısından önemli bir araç olma yolunda ilerlediği söylenebilir. Özellikle interaktif ders kitapları, üç boyutlu video ve resimlerin yanı sıra yaklaşık 20,000 eğitimsel ve bilimsel uygulama ile iPad, eğitim alanında önemli bir araç haline gelmektedir (Apple, 2012).

Eğitim alanında önemi artan iPad'in kaçınılmaz olarak bilgi hizmetleri alanında da kullanılması ve kütüphanelerin bu araçları ödünç vermeye başlaması beklenebilir. Özellikle, üniversitelerdeki eğitim faaliyetini destekleyen akademik kütüphanelerin, eğitim alanında oldukça kullanışlı bir araç olan iPad'i kullanıma sunması gerek eğitim faaliyetlerinin desteklenmesi, gerekse üniversite camiasındaki saygınlığın ve tercih edilirliğin arttırılması açısından önemli bir adım olacaktır. Ancak, kütüphanelerin bu araçları kullanıma sunmada, göz önünde bulundurmaları gereken bazı önemli hususlar bulunmaktadır. Bu hususlar teknik detaylar ile ilgili olduğu kadar, ödünç verme prosedürü ve politikaları ile de ilgilidir. Kütüphaneler, bu pahalı sayılabilecek araçları kullanıma sunmadan önce, kaybolma ya da hasar görme ihtimaline karşı oluşturacakları prosedürler ve kurallar ile gerekli önlemleri almalıdırlar. Kütüphanelerin, ayrıca, yazılım ve uygulamalar gibi konuları teknik detaylar başlığı altında değerlendirmeleri ve gerekli düzenlemeleri yapmaları gerekmektedir. Bahsedilen bu hususlar, iPad'lerin etkin bir şekilde kullanıma sunulması açısından önemlidir.

2011 yılında, Koç Üniversitesi mensuplarına ödünç verilmek üzere iPad 2 ürününü satın alan Suna Kıraç Kütüphanesi, bu araçların ödünç verme prosedürünün nasıl olacağı, hangi kurallar ışığında ödünç verilebileceği ve yazılım ya da uygulamalar ile ilgili teknik problemlerin nasıl halledilebileceği gibi konularda bir proje başlatmıştır. Ödünç verilme aşamasında ise, ilgili projeye, kullanıcıların iPad kullanım amaçlarının 
anket yolu ile tespit edilmesi de eklenmiştir. Bu sayede ödünç verilme aşamasında karşılaşılabilecek sorunlara karşı gerekli önlemlerin alınması ve bu sorunların en aza indirilmesine çalışılmıştır.

Bu çalışma, bahsedilen iPad ödünç vermeye hazırlık ve ödünç verme sürecinde Suna Kıraç Kütüphanesi'nin edindiği bilgileri ve tecrübeleri içermektedir. Akademik kütüphanelerin bu tip elektronik araçları kullanıma sunarken edindikleri bilgileri ve tecrübeleri paylaşması, bu konuda benzer çalışmalar yapacak olan diğer kütüphaneler için yol gösterici olacaktır.

\section{Önceki Çalışmalar}

2010 yılında piyasaya sürülen iPad, yeni bir elektronik araçtır. Bu sebeple, kütüphanecilik literatürüne baktığımızda, bu araçların ödünç verme hizmetlerine entegrasyonunu inceleyen yayınların tarih olarak oldukça yeni ve sayıca az olduğu görülmektedir. Özellikle, iPad kullanımlarını inceleyen kullanıcı çalışmalarının yeterli sayıda olmadığı anlaşılmaktadır.

Kütüphanelerin, iPad ödünç verme ile ilgili prosedürleri ve kuralları incelendiğinde, kendi kullanıcılarının beklentilerine ya da kurumsal şartlarına göre bu kural ve prosedürleri oluşturdukları görülür. Genel ödünç verme süresi olarak saatlik ödünç veren kurumlardan, bir hafta süreyle ödünç veren kurumlara kadar farklı zaman dilimlerini tercih eden kurumları görmek mümkündür (Thompson, 2011; Obst, 2010; Anderson ve Weatherbee, 2012; Bennet ve Hutchings 2011; Libraries, 2012).

Obst (2010), görev yaptığı Münster Universitesi Tıp Kütüphanesinde iPad'lerin ödünç verilmeyen referans kitaplarının elektronik versiyonlarının okunması amacı ile öğrencilere 1 günlüğüne ödünç verildiğini belirtmektedir. Obst'a göre, bu şekilde duyurulan ve ödünç verilen iPad'ler daha sonra interaktif özelliklerinin keşfedilmesi ile öğrenciler için önemli bir araca dönüşecektir.

Ödünç verme süreleri dışında, iPad'lere ilişkin gecikme, zarar görme ve kaybolma ile ilgili ücret politikalarında da farklılıklar görülmektedir (Thompson, 2011; Anderson ve Weatherbee, 2012; Bennet ve Hutchings, 2011; Libraries, 2012). Ayrıca, bazı üniversite kütüphanelerinin iPad ödünç vermeden önce, gecikme ya da zarar görme durumlarında uygulanacak yaptırımlara ilişkin kullanıcılarına bir yazılı belge ya da sözleşme imzalattıkları saptanmıştır (Obst, 2010; Bennet ve Hutchings 2011). İmzalanan bu sözleşme kullanıcılar açısından gecikme ya da zarar verme konusunda caydırıcı olması sebebi ile önemli görülebilir.

Ödünç verme sürelerine ve ceza politikalarına ilişkin hususlar dışında teknik konularda literatürdeki çalışmalarda ele alınmıştır. Bu çalışmalarda iade edilen iPad'lerin yazılımlarının güncellenmesi, kullanıcılar tarafından iPad'lere indirilen program ya da uygulamaların silinmesi ve tüm iPad ayarlarının ödünç verilmek üzere sıfırlanması gibi 
işlemler için Apple firmasına ait iTunes programının kullanılması önerilmektedir. Bu program yardımı ile değişik tarihler için yedek dosyalar (back up) oluşturulabilmekte ve iade edilen iPad'ler bu yedek dosyaların tekrar yüklenmesi ile (restore from back up) ödünç verilmeden önceki hallerine getirilmektedirler (Thompson, 2011; Anderson ve Weatherbee, 2012; Bennet ve Hutchings, 2011; Eichenlaub, Gabel, Jakubek, McCarthy ve Wang, 2011).

Bazı kütüphaneler, yeni uygulamaların yüklenmesini ya da yüklenmiş uygulamaların silinmesini iPad'in ayarlar bölümünü kullanılarak engellenme yoluna gitmişlerdir (Thompson, 2011; Bennet ve Hutchings, 2011). Bu şekilde iPad'lerin tekrar yükleme işini kolaylaştırmayı amaçlamışlardır. Ancak Thompson (2011), bu engelleme sebebi ile kullanıcıların bazı sitelerden elektronik kitap indiremediklerini belirtmektedir.

Kütüphaneler tarafından ödünç verilecek iPad'lerin içerisinde hangi uygulamaların yüklü olması gerektiği konusu, üzerinde durulan bir başka önemli konudur. Yüklenecek uygulamalara karar vermede hizmet verilen kullanıcı grubunun niteliğinin önem kazandığı ve bu sebeple hizmet verilen gruba göre farklı türde uygulamalar yüklendiği görülmektedir. Thompson (2011), yüklenecek uygulamalara karar verirken, öncelikle App Store sayfası üzerindeki kullanıcı yorumlarını incelemekte fayda olduğunu belirtir. Ayrıca, Thompson'a göre, ilgilenilen uygulama ile ilgili diğer web sayfaları üzerindeki bilgi ve yorumlar da dikkatlice incelenmeli ve uygulamanın yüklenmesine bu şekilde karar verilmelidir.

Kütüphanelerin yüklediği uygulamalar, her ne kadar hizmet verilen kesime göre farklılık gösterse de, iBooks, Stanza, GoodReader gibi elektronik kitap okumaya ya da indirmeye olanak sağlayan uygulamalar birçok kütüphanenin ortak olarak kullandığı uygulamalar olarak dikkati çekmektedir (Thompson, 2011; Obst, 2010; McDermott, 2011).

Oxford, Stanford ve MIT gibi birçok önemli üniversitenin ders içeriklerine, notlarına ve konu anlatımlı ders videolarına erişim sağlayan iTunes U uygulaması, kütüphanelerin ortak olarak kullandığı bir başka uygulama olarak dikkati çekmektedir. Apple firması tarafından ücretsiz olarak erişime sunulan bu uygulama, eğitim alanında önemlidir (Thompson, 2011; Obst, 2010; Lotts ve Graves, 2011).

Kütüphanelerin iPad'lere yüklediği bir başka uygulama türü, web sayfalarına hızlı ve kolay erişim sağlayan uygulamalardır. Özellikle, sosyal medya sitelerine (Facebook, Twitter), haber amaçlı web sayfalarına (BBC, CNN, New York Times vb.) ve bilimsel sayfalara (iSSRN, Nature News, Wolfram Alpha, World Cat vb.) erişim sağlayan uygulamalar en çok tercih edilenlerdir (Barile, 2011; Thompson, 2011; Obst, 2010; Bennet ve Hutchings, 2011). 
Münster Universitesi Tıp Kütüphanesi'ne ödünç verilen iPad'lere yüklenen uygulamaların kullanımlarını inceleyen Obst (2010), eğitim alanında önemli bir uygulama olan iTunes $\mathrm{U}$ uygulamasının çok kullanılmadığını vurgular ve Tıp alanına yönelik olarak yüklenmiş olan toplam 75 uygulamadan, en çok kullanılanın Papers isimli kaynakça yönetim uygulaması olduğunu belirtir.

iPad ödünç veren bazı kütüphaneler, kullanıcılarının bu araçları ne amaçla kullandığı ve bu araçlarla ilgili ne gibi beklentilerinin olduğunu ölçmeye çalışmışlardır. Bu tip bir çalışma yapan Bennet ve Hutchings (2011), Cardinal Stritch Üniversitesi Kütüphanesi kullanıcıları için bir anket uygulamıştır. Ankette, kullanıcılara neden iPad ödünç aldıkları sorusunu yönelten Bennet ve Hutchings (2011), ödünç almada \%60 oranında merak unsurunun etkili olduğunu ortaya koymuşlardır. Daha sonra en çok tercih edilen seçenek olarak diğer seçeneği \%21 oranında işaretlenirken, \%9 oranında internette gezinmek, $\% 5$ oranında ise belli bir uygulamayı kullanmak ve iPad'i elektronik okuma aracı olarak kullanma seçenekleri işaretlenmiştir.

Merak unsurunun iPad ödünç almada etkili olduğunu ortaya çıkartan bir başka çalışma ise Thompson (2011), tarafından Briar Cliff Üniversitesi'nde yapılmıştır. Thompson (2011), konuşma şansı bulduğu kullanıcıların, iPad'in nasıl bir araç olduğunu merak ettiklerini ve bu yüzden onu ödünç aldıklarını belirtir. Bu çalışmalarda ortaya çıkan merak unsurunun ödünç almada etkili olmasını iPad'in yeni bir araç olmasına ve kullanıcılar tarafından çok iyi bilinmemesine bağlayabiliriz. Her ne kadar kullanıcılar tarafından çok iyi bilinmese de, yapılan araştırmalarda iPad'in genel olarak kullanıcılar üzerinde olumlu bir etki bıraktığı saptanmıştır. Bennet ve Hutchings (2011), yaptıkları araştırmada kullanıııların \%55'inin iPad'leri etkileyici bulduklarını saptamışlardır. Obst (2010) ise bu oranın \%60 olduğunu ortaya koymuştur.

Bennet ve Hutchings (2011), çalışmalarında kullanıcıların ödünç aldıları iPad'leri öncelikle hangi amaçla kullandıklarını incelemeye çalışmışlardır. Bu çalışmaya katılan kullanıcılar, iPad'leri öncelikle internette gezinmek için (\%67) kullandıklarını belirtmişlerdir. Daha sonra sırası ile diğer (\%16), belli bir uygulamayı kullanmak (\%12) ve iPad'i elektronik okuma aracı olarak kullanma (\%5) seçenekleri gelmektedir.

Thompson (2011), iPad üzerinde en çok bir internet tarayıcısı olarak kullanılan Safari'nin kullanıldığını tespit etmiştir. Buna dayanarak, bu çalışmaya katılan kullanıcıların da yoğun olarak iPad'lerden internet için faydalandıklarını söylememiz mümkündür. Yapılan çalışmalarda iPad'lerin özellikle internet için kullanılmasının ana sebebi, diz üstü bilgisayarlara göre daha taşınılabilir ve hafif olması olarak görülebilir. Ayrıca, yine dizüstü bilgisayara göre şarj etmeden kullanabilme süresinin iPad'lerde daha uzun olduğu göz önünde bulundurulmalıdır. 
Obst (2010) ise, çalışmasında kullanıcıların iPad'leri ve uygulamaları öncelikle elektronik kitap okumak için kullandığını ve daha sonra sırası ile literatür taraması yapmak, kaynakça yönetiminde yararlanmak, derslerde kullanmak, ders videoları izlemek gibi akademik amaçlarla kullandıklarını belirtir.

iPad akademik hayatta oldukça kullanışlı bir araç olabilmektedir. Ryerson Üniversitesi Kütüphanesi'nde görev yapan bir grup kütüphaneci, seçtikleri dört öğrenciye dağıttıkları iPad'ler ile öğrencilerin akademik hayatlarında bu araçları nasıl kullandıklarını saptamaya çalışmışlardır. Öğrencilerin ortak olarak belirttikleri nokta ise, iPad'lerin yaptıkları akademik çalışmaları tamamen değiştirmesidir. iPad'ler ile kağıtsız olarak çalıştıklarını vurgulayan öğrenciler, kişisel ve akademik hayatlarını organize etmede iPad'lerin büyük kolaylık sunduğunu belirtirler. Bu durumda, özellikle ders materyallerinin dijital ortama aktarılarak çeşitli uygulamalar aracılığı ile okunabilir kılınmasının büyük bir etkisi olduğu görülmektedir (Eichenlaub, Gabel, Jakubek, McCarthy, ve Wang, 2011).

Akademik amaçlar dışında, oyun oynamak amacı da iPad kullanımında etkili olabilmektedir. iPad ödünç alan kullanıcılardan uygulamalara yönelik önerilerini toplayan Bennet ve Hutchings (2011), oyun uygulamalarının talep edildiğini saptamıştır. Benzer şekilde Obst (2010), iPad kullanımında akademik amaçların ardından oyun oynama amacının geldiğini vurgular.

iPad sahibi olan kullanıcılar, uygulama önerisi ya da teknik destek almak için iPad ödünç veren kütüphaneleri ziyaret edebilmektedirler (Thompson, 2011; Obst, 2010). Bu sonuca bakarak, iPad'lerin kullanıcılar ile kütüphaneler arasındaki iletişime dolaylı da olsa bir katkıda bulunduğu söylenebilir.

2010 yılında piyasaya sürülen iPad, yeni bir elektronik araçtır. Bu sebeple, kütüphanecilik literatürüne baktığımızda, bu araçların ödünç verme hizmetlerine entegrasyonunu inceleyen yayınların tarih olarak oldukça yeni olduğu ve sayıca oldukça az olduğu görülmektedir. Özellikle, iPad kullanımlarını inceleyen kullanıcı çalışmalarının yeteri sayıda olmadığı anlaşılmaktadır.

\section{Koç Üniversitesi Suna Kıraç Kütüphanesi iPad Ödünç Verme Politikası ve Prosedürü}

Suna Kıraç Kütüphanesi kullanıcılarına sunmak üzere satın aldığı 5 iPad için gerekli olan politika, prosedür ve sorumluluk sözleşmesi ile ilgili bir dizi çalışma yürütmüştür. Bu çalışmaların ilk ayağını iPad ödünç veren kurumların tespit edilmesi oluşturmuştur. Tespit edilen kurumlarda varsa iPad ödünç verme politikaları incelenmiş, oluşturulacak olan politika belgesi için fikir alınmıştır. Alınan fikirler ve yapılan inceleme çalışmaları sonucunda ödünç verme politikası ile ilgili aşağıda belirtilen konularda kararlar alınmış ve uygulamaya geçirilmiştir: 


\section{Yetkili Kullanıcılar}

$\diamond \quad$ Politika belirleme sürecinde öncelikle kimlerin bu hizmeti alabileceği belirlenmiştir. Bu anlamda tüm öğrenci, öğretim üyesi ve çalışanların geçerli kimlik kartlarını göstermek koşuluyla iPad ödünç alabilecekleri kararlaştırılmıştır.

$\diamond \quad$ Mezunlar, dış üyeler ve misafir kullanıcılar iPad sayısının yeterli olmaması ve ödünç verme sürelerinin bu tip kullanıcılar için kısa olmasından dolayı, hizmetin dışında tutulmuşlardır.

\section{Kullanım süreleri ve haklar}

$\diamond \mathrm{Bu}$ hizmetten kimlerin yararlanabileceğinin belirlenmesinin ardından, iPad'i ne kadar bir zaman dilimi için ödünç alabilecekleri belirlenmeye çalışılmıştır. Dolaşıma sürülen iPad sayısının az oluşu, ödünç verme sürelerini de kısa tutmayı gerektirmiştir. Bu aşamada dört saatlik, günlük, üç günlük ve haftalık olarak ödünç verme fikri üzerinde durulmuş ve sonuç olarak üç günlük ödünç verme süresinin makul olacağı kararlaştırılmıştır.

$\diamond$ Her bir kullanıcı aynı anda sadece bir iPad ödünç alabilecektir. Ödünç alma işlemi sırasında iPad ile birlikte koruyucu akıllı kapak, çanta, adaptör de ödünç verilmektedir. Her bir materyal için kütüphane sisteminde ayrı ayrı kayıt açılmıştır ve üzerlerine bu kayıtlara ait barkod numaraları yapıştırılmıştır.

$\diamond \quad$ iPad ödünç almak isteyen kullanıcılar için herhangi bir rezervasyon sistemi oluşturulmamış, ilk gelen alır prensibiyle ödünç verilme işlemi yürürlüğe konmuştur. Masaya konulan, görsel içeren ve çift yüzlü “iPad In/iPad Out” yazısı hem kullanıcının iPad olup olmadığını algılaması, hem de bu hizmetin tanıtımının yapılması açısından yardımcı olmuştur.

$\diamond \quad$ iPad'lerin dolaşıma çıkarılacağı (ödünç verileceği) saatlerde, üzerinde düşünülmesi gereken bir başka konu olmuştur. Özellikle teknik destek sağlayacak nitelikli personelin bulunduğu gün ve saatler ödünç verme için belirlenmiştir (Hafta içi, 08:30-16:30). Nitelikli personel ile kullanıcıların iPad'ler ile ilgili sorularına cevap verilmesinin dışında, yazılımdan kaynaklı sorunlara da müdahale edilmesi ön görülmüştür. Daha sonra kütüphane hizmet saatlerinin 7/24 olması sebebiyle bu saatler yeniden gözden geçirilmiş ve genişletilmiştir (08:30-22:30).

\section{Sorumluluk, yaptırım ve cezalar}

$\diamond \quad$ Kütüphane olarak mevcut teknik ekipman ödünç verme politika ve prosedürlerine paralel bir sorumluluk sözleşmesi hazırlanmıştır. iPad ödünç alacak kişinin belirlenen kuralları iyice anlaması ve hazırlanan iPad Sorumluluk Sözleşmesi'ni imzalaması istenmektedir.

$\diamond \quad$ Kullanıcılar için daha önceden belirlenmiş olan gün sınırlamasının yanına, gecikme durumu için bazı cezai müeyyideler de oluşturulmuştur. Burada günlük 25 TL gibi bir rakam gecikme bedeli olarak tespit edilmiştir. Bu bedel kütüphanenin uyguladığı en yüksek ceza miktarıdır. 
$\diamond$ Gecikme cezasının dışında materyal kayıp ve hasar durumunda ödenecek miktarlarda belirlenmiştir. iPad kaybedilmesi halinde cihaz bedeli olarak $1300 \mathrm{TL}$, işlem parası için 32TL, adaptör için 50 TL, akıllı kapak için 50 TL ve taşıma çantası için 80 TL olarak belirlenmiştir.

\section{Yüklenen uygulamalara ve yazılıma ilişkin teknik konular}

$\diamond$ Öncelikle iPad'lere hangi uygulamaların yükleneceği belirlenmeye çalışılmıştır. Yapılan incelemeler sonucunda, ilk etapta, iBooks, Stanza gibi elektronik kitap indirmeye ve okumaya yarayan uygulamalar ile Science360, SSRN(Social Science Research Network) ve iTunes U gibi bilimsel içeriklere erişim sağlayan uygulamaların yüklenmesi kararlaştırılmıştır. Belirlenen bu uygulamalar iPad ödünç veren diğer üniversite kütüphaneleri incelenerek saptanmıştır. Ayrıca, Koç Üniversitesi öğrencilerinin sıklıkla kullandığı, kurum içi bilgi sistemi olan KUAIS uygulamasının ve kütüphane sayfasına mobil erişim sağlayan Library Anywhere uygulamasının yüklenmesi uygun bulunmuştur.

$\diamond$ Yüklenen uygulamalar dışında, elektronik rezerv kaynaklarının birer kopyası da iPad'ler içerisine yüklenmiştir.

$\checkmark$ Danışma masasında bulunan personel bilgisayarlarına iPad yazılımlarının ve uygularlarının güncellenmesi için iTunes programı yüklenmiştir. İade edilen her iPad, veri kablosu aracılığı ile bu bilgisayarlara bağlanarak, daha önce iTunes programında oluşturulan yedek dosyaların (back up) geri yüklenmesi (restore) ile ödünç alınma öncesi haline getirilmektedir. Bu işlem sırasında iPad ödünç alan kullanıcıların indirdiği diğer uygulamalar silinmektedir.

$\diamond$ Personele, güncellemelerin nasıl olacağı ve uygulamaların nasıl yükleneceği gibi teknik konularda bir hizmet içi eğitim verilmiştir. Ayrıca personel için bir prosedür hazırlanmıştır. Bu prosedürde ekipmanın kontrolü, ödünç verme işlemi sırasında yapılacak bilgilendirme, yüklenecek uygulamalar gibi maddeler bulunmaktadır.

\section{Tanıtım ve duyurular}

$\diamond \mathrm{Bu}$ hizmetin duyurusu için posterler hazırlanmış ve kütüphanede görülebilir noktalara konulmuştur.

$\diamond \quad$ Kayıt masasına ve kütüphane girişinde bulunan ekranlara konuyla ilgili görseller konulmuştur.

$\diamond$ Tüm kullanıcılara bu hizmetimizi tanıtıcı duyuru e-postaları atılmıştır.

$\diamond$ Duyuru ve tanıtım faaliyetleri için sosyal medya yoğun bir şekilde kullanılmıştır. 


\section{Koç Üniversitesi Kullanıcılarının iPad Kullanım Özellikleri ile İlgili Bulgular ve Yorum}

iPad kullanımına ilişkin bulgular, tarih aralığı olarak Kütüphane'ye sağlanan ilk 5 iPad'in kullanıldığı dönem olan, Eylül 2011 - Mayıs 2012 ile sınırlıdır. Veri toplamaya yönelik hazırlanan anketler ise, bu araçları en çok ödünç alan grup olan lisans öğrencilerine uygulanmıştır.

Koç Üniversitesi kullanıcılarının iPad kullanımına ilişkin elde edilen verilere geçmeden önce, bu araçların ödünç verilme oranları ile ilgili bilgi vermekte fayda vardır. Eylül 2011 - Mayıs 2012 arasında iPad'lerin toplam ödünç alınma sayısı 597 olmuştur. Ödünç alan kullanıcı türüne baktığımızda en fazla Lisans Öğrencilerinin ödünç aldığı görülmektedir. Kullanıcı türüne göre toplam ödünç alınma sayıları Tablo I'de görülmektedir.

Tablo I. Kullanıcı Türüne Göre iPad Ödünç Alma Sayıları

\begin{tabular}{lr}
\hline Kullanıcı Türü & Ödünç alınma sayısı \\
\hline Personel / Akademisyen & 110 \\
Yüksek Lisans / Doktora & 57 \\
Lisans Öğrencileri & 430 \\
\hline Toplam & $\mathbf{5 9 7}$ \\
\hline
\end{tabular}

iPad ödünç alan lisans öğrencilerine yönelik, Mart - Mayıs 2012 tarihleri arasında, uyguladığımız ankete toplam 81 öğrenci katılmıştır.

Ankete katılan öğrencilere öncelikle iPad ödünç almalarının en önemli sebeplerinin ne olduğu sorusu yöneltilmiştir. Birden fazla seçeneğin işaretlenebildiği bu soruda, en çok tercih edilen seçeneğin \%46 oranında "iPad'in kolay taşınabilirliğinden faydalanma" olduğu görülmektedir. "Elektronik okuma aracı olarak kullanma" sebebi ise \%44 oranıla ikinci sırada gelmektedir. Elektronik okuma aracı olarak kullanmak ile kolay taşınabilirliğinden faydalanmak seçeneklerinin birbirlerine çok yakın olduğu ve nerdeyse eşit oranda tercih edildikleri görülmektedir. Bu seçeneklerin ardından sırası ile internete girmek, merak, özel bir iPad uygulamasını kullanma ve diğer seçeneklerinin geldiği görülmektedir. Tablo II'de kullanıcıların iPad ödünç almalarının en önemli sebeplerini görmek mümkündür. 
Tablo II. iPad Ödünç Alma Sebepleri

\begin{tabular}{lrr}
\hline Ödünç alma sebepleri & İşaretlenme sayısı & Oran \% \\
\hline Kolay taşınabilirliğinden faydalanmak & 38 & 46 \\
Elektronik okuma aracı olarak kullanmak & 36 & 44 \\
İnternete girmek & 17 & 21 \\
Merak & 14 & 17 \\
Özel bir iPad uygulamasını kullanmak & 5 & 6 \\
Diğer & 2 & 2 \\
\hline
\end{tabular}

Ankete katılan öğrenciler iPad'leri öncelikle kolay taşınabilirliğinden faydalanmak amacı ile ödünç almaktadırlar. Daha önce oldukça esnek ve kullanışlı olduğundan söz ettiğimiz iPad'lerin, kolay taşınabilir olmalarından dolayı ödünç alınmaları şaşırtıcı bir sonuç olarak görülmemelidir. Ayrıca, ankete katılan öğrencilerin iPad'lerle ilgili bilgi sahibi oldukları ve bu yüzden merak sebebi ile ödünç almaya daha az oranda yöneldikleri söylenebilir. Elektronik okuma için ödünç alınmasında da, iPad'ler hakkında öğrencilerin önceden bilgi sahibi olmalarının etkili olduğu düşünülebilir. Elektronik okuma aracı olarak kullanmanın yüksek, merak unsurunun ise oran olarak düşük çıkması literatürdeki bazı çalışmalara göre farklı bir sonuç olarak göze çarpmaktadır (Thompson, 2011; Bennet ve Hutchings, 2011). Bu farkın sebebini iPad'lerin her geçen gün daha çok yaygınlaşması ile açıklayabiliriz. Ayrıca, iPad'lere yüklenen elektronik rezerv kaynaklarının da, Koç Üniversitesi öğrencilerinin iPad'leri elektronik okuma aracı olarak kullanmalarında etkili olduğu düşünülebilir.

iPad kullanımı ile ilgili olarak, öğrencilere yönelttiğimiz bir diğer soru ise iPad'i ödünç aldıktan sonra en çok hangi özelliğini kullandıkları olmuştur. Birden fazla seçeneğin işaretlenebildiği bu soruda, \%62 oranı ile en çok internet özelliğinden faydalanıldığı ortaya çıkmışır. Daha sonra sırası ile elektronik okuma aracı, özel bir iPad uygulaması ve diğer seçenekleri gelmektedir. Tablo III'de kullanıcıların iPad üzerinde en çok kullandıkları özellikleri görmek mümkündür.

Tablo III. iPad Üzerinde En Çok Kullanılan Özellik

\begin{tabular}{lcc}
\hline En çok kullanılan özellik & İşaretlenme sayısı & Oran \% \\
\hline İnternet & 51 & 62 \\
Elektronik okuma aracı & 26 & 32 \\
Özel bir iPad uygulaması & 14 & 17 \\
Diğer & 8 & 10 \\
\hline
\end{tabular}


iPad ödünç alan ve ankete katılan öğrenciler öncelikle "internet" özelliğini kullanmaktadırlar. Ödünç alma sebeplerinde yüksek çıkmayan internetin, ödünç aldıktan sonra çok tercih edildiği görülmektedir. Aynı şekilde, her ne kadar ödünç alma sebeplerinde daha yüksek bir oran olarak görülse de, ödünç aldıktan sonra "elektronik okuma" seçeneğinin düşük olduğu dikkati çekmektedir. Buradan yola çıkarak ödünç verilen iPad'lere yeterli sayıda ve türde elektronik kitabın yüklenmediğini düşünmemiz mümkündür. Kullanım özellikleri ile ilgili sonuçlar literatürdeki bazı çalışmalarla benzerlik göstermektedir (Bennet ve Hutchings, 2011). Diğer seçeneğini işaretleyen kullanıcıların çok büyük bir bölümü çeşitli oyun uygulamalarından bahsetmişlerdir. Bu anlamda, literatürdeki bazı sonuçlara paralel olarak, iPad'lerin oyun amaçlı da kullanıldığını söyleyebiliriz (Obst, 2010).

Anketin kalan iki sorusu açık uçlu sorulardır. Bu sorulardan ilki ankete katılan öğrencilerden uygulama önerisi almayı amaçlamaktadır. 31 kullanıc uygulama önerisinde bulunmuştır. Yapılan uygulama önerilerine bakıldığında tıp ya da işletme gibi alanlara yönelik bilimsel uygulamaların yanı sıra sözlük gibi referans kaynaklarına ve gazetelere yönelik uygulamaların arttırılması önerilmiştir. Oyun uygulamalarına yönelik talep de az sayılmayacak bir orandadır.

Açık uçlu olarak sorduğumuz son soruda ise ankete katılan öğrencilere öneri ya da yorumları sorulmuştur. 26 öğrencinin cevapladığı bu soruda en çok dile getirilen konunun mevcut iPad sayısının ve özellikle ödünç alma süresinin (3 gün) arttırılması olduğu dikkat çekmektedir. Ayrıca, hizmetten duyulan memnuniyet de birçok kullanıcı tarafından vurgulanmıştır.

Bu hizmetin verilmeye başlanmasından bugüne kadar en çok karşılaşılan sorun adaptör/veri kablosunda yaşanan sıkıntı olmuştur (sekiz kez kablo arızası ortaya çıkmıştır). Bunun yanında iki kez teknik bakım desteği almak gerekmiştir. Bu problemler toplam 597 defa ödünç alınma sonrasında ortaya çıkmıştır. Karşılaşılan bu ve benzeri sorunlar için iPad'lerin sigortalanması kararlaştııılmıştır. Bilgi İşlem Bölümü'nün desteği ile gerçekleştirilen bu işlem sayesinde ileride oluşabilecek kayıp çalıntı ve diğer daha büyük sorunlar için de tedbir alınmıştır. Ayrıca, ceza miktarları ve gecikme durumu ile ilgili sonuçlar da şaşırtıcıdır. Sadece beş kişi gecikmeden dolayı ceza ödemek durumunda kalmıştır. Bu durumun ceza miktarının yüksek olması ve imzalatılan sorumluluk sözleşmesinin caydırıcı etkisi ile ortaya çıktığı söylenebilir.

\section{Sonuç ve Öneriler}

iPad ödünç vermeyi planlayan kütüphaneler için politika oluşturma açısından öneriler sunmayı ve aynı zamanda kullanıcıların iPad kullanım özelliklerini araştırmayı amaçlayan çalışmamızda ulaştı̆̆ımız sonuçlar şu şekilde sıralanabilir:

$\diamond$ Gerek literatürdeki çalışmalara, gerekse Koç Üniversitesi öğrencilerine yönelik yapılan bu çalışmaya bakıldığında, kullanıcıların iPad'lere yoğun ilgi gösterdiğini 
söyleyebiliriz. Çalışmamızda 597 olarak belirtilmiş olan toplam ödünç verme sayısının, iPad sayısının azlığı göz önünde bulundurulduğunda, yüksek bir sayı olduğu söylenebilir. Suna Kıraç Kütüphanesi'nin ödünç verilen iPad sayısını arttırması bu yüksek ödünç alına sayısının ve iPad'lere olan yoğun talebin bir sonucudur. Önceleri 5 olan iPad sayısı, daha sonra 20'ye çıkartılmıştır.

$\diamond$ Kütüphaneler iPad ödünç verirken sırası ile şu konular ile ilgili politika ve prosedürlerini belirlimledirler:

- Yetkili kullanıcılar,

- Kullanım süreleri ve haklar,

- Sorumluluk, yaptırım ve cezalar,

- Yüklenen uygulamalara ve yazılıma ilişkin teknik konular.

$\diamond \quad$ Kütüphaneler belirttiğimiz bu konulara ilişkin politika ve prosedürleri saptarken kurumsal şartları ve kullanıc beklentilerini göz önünde bulundurmalıdırlar. Bu bağlamda kullanıcı beklentilerinin saptanması da önem kazanmaktadır.

$\diamond$ Ödünç verilen iPad'ler için gecikme ya da zarar görme durumlarına karşı imzalatılacak bir sözleşmenin, hukuksal açıdan değilse de, caydırıcılık açısından önemi vardır. Ayrıca, yine iPad'lerin sigortalanması, pahalı sayılabilecek bu araçların görebileceği zararlar konusunda tedbir almak için gerekli olabilir.

$\diamond$ Teknik açıdan iPad'lerin ödünç vermeye hazırlanması için iTunes programı kullanılabilir bir araç olarak dikkati çekmektedir. Bu program özellikle uygulamaların tekrar yüklenmesi ve iPad yazılımlarının güncellenmesi açısından önemlidir.

$\diamond \quad$ iPad'ler üzerine yüklenecek uygulamaların belirlenmesi için kullanıcı beklentilerinin saptanması önemlidir. Yüklenecek uygulamalar bu beklentilere göre belirlenmeli ya da daha önceden yüklenen uygulamalar güncellenmelidir.

$\diamond$ iBooks ve Stanza gibi elektronik kitap okumaya ve indirmeye yarayan uygulamaların yanı sıra, iTunes U gibi üniversitelerin ders içeriklerine erişim sağlayan uygulamalar da literatürde çok tercih edilen uygulamalar olmuştur. Sosyal medya sitelerine, haber amaçlı web sayfalarına ve bilimsel sayfalara erişim sağlayan uygulamalar da tercih edilmektedir. Ayrıca, oyunlara yönelik uygulamalar da kullanıcılar tarafından kullanılmaktadır.

$\diamond$ Çalışmamıza katılan kullanıcılar iPad ödünç almadaki en önemli sebeplerini kolay taşınabilirliğinden ve elektronik okuma özelliğinden faydalanmak olarak göstermişlerdir. Öte yandan, ödünç alınan iPad'lerde kullanılan özellikler, ödünç alma sebeplerine göre farklılık göstermiştir. Örneğin, elektronik okuma özelliği, iPad ödünç alınma sebebine nazaran daha düşük bir oranda tercih edilmiş ve internetin ardından ikinci sırada yer almıştır. Bunun nedeni iPad'lere okumaya yönelik olarak yeterli ve çeşitli türde elektronik kitabın ya da okuma materyallerinin yüklenmemesi olarak görülebilir. Ancak, yine de elektronik okuma aracı olarak kullanılma, iPad ödünç almada oldukça önemli bir neden olarak kendini göstermektedir. 
Üniversitelerdeki eğitim faaliyetini destekleyen akademik kütüphanelerin, eğitim alanında oldukça kullanışlı bir araç olan iPad'i kullanıma sunarak, bu faaliyete olumlu bir katkıda bulunabilecekleri söylenebilir. Bunun yanın sıra, bu tip araçları ödünç vermek kütüphanelerin saygınlıkları ve tercih edilirlikleri açısından da önemli görülebilir. Öte yandan, iPad ödünç veren kütüphanelerin kullanıcılarının beklentilerini saptamaları ve onların kullanım özelliklerini belirlemeleri hizmet kalitesini arttırmada faydalı olacaktır. Literatüre bakıldığında kütüphanelere fayda sağlayacak, iPad'lere yönelik bu tip kullanıcı çalışmalarının yeterli sayıda olmadığı dikkati çekmektedir. Kullanıcı merkezli ödünç verme hizmeti açısından bu çalışmaların sayısının artması büyük önem taşımaktadır.

\section{Kaynakça}

Anderson, S. ve Weatherbee, S. (2012). Growing a technology equipment service in an academic library. Computers in Libraries, 32(6), 6-8.

Apple in Education. (2012). 4 Aralık 2012 tarihinde http://www.apple.com/education/ipad adresinden erişildi.

Barile, L. (2011). Mobile technologies for libraries: A list of mobile applications and resources for development. College ve Research Libraries News, 72(4), 222.

Bennet, J. ve Hutchings, J. (2011). Circulating iPads in an Academic Library [PowerPoint slides].

Eichenlaub, N., Gabel, L., Jakubek, D., McCarthy, G. ve Wang, W. (2011). Project iPad. Computers in Libraries, 31(7), 17.

Griffey, J. (2012). The rise of the tablet.(Chapter 2)Gadgets and Gizmos: Personal Electronics and the Library. Library Technology Reports, 48(3), 7.

Libraries Loaning iPads. (2012). 4 Aralık 2012 tarihinde http://kraftylibrarian.com/?p=1860 adresinden erişildi.

Lotts, M. ve Graves, S. (2011). Using the iPad for reference services: Librarians go mobile. College ve Research Libraries News, 72(4), 217.

McDermott, E. (2011). iPad 2 for Librarians. Searcher, 19(6), 8-11.

Obst, O. (2010). iPad lending project: First results. Journal of the European Association for Health Information and Libraries, 6(4), 39.

Thompson, S. Q. (2011). Setting up a library iPad program: Guidelines for success. College ve Research Libraries News, 72(4), 212. 